ON THE INJURIES

\author{
ARISTNG FROM
}

USING COMMON PESSARTES;

WITH SUGGESTIONS FOR A NEW ONE, BETTER CALCULATED TO REMEDY THE EVILS FOR WHICH THEY ARE APPLICABLE.

By Charles Clay, Esq., Surgeon, Piccadilly, Manchester, Lecturer on Medical Jurisprudence, \&c.

I HAFE for some years had my attention drawn to the evils arising from wearing common pessaries, and having had numerous opportunities of witnessing the effects from a variety of such instruments, I feel astonished that the well-known and admitted skill and ingenuity of our profession should present us with no better means for securing the object in view than the present ill-contrived articles sold and used under the name of pessaries. I think it difficult to reconcile the rapid march of improvement in the various departments of medical science with the means proposed for the relief of prolapsus uteri by pessary, in which there has not been any decided improvement for ages, the most modernised article being as inefficient and as contrary to the rules of common sense as those first proposed by the earliest obstetric writers.

It is from a knowledge of these facts that I have presumed to suggest to the profession, throngh the medium of your very valuable Journal, a new pessary, which in my humble opinion is much better calculated to retain the uterus in its proper position, and with the far more valuable adjunct, that of allowing the vaginal canal to assume its natural dimensions; thus rapidly tending to obliterate the cause, and thereby rendering the further use of the pessary quite unnecessary. All pessaries now in use only give very temporary relief, and that by increasing the evil sought to be remedied. It is preposterous for a moment to suppose, that the diseases for which pessaries are required, and which are owing entirely to a laxity of the vaginal canal, can be cured, or even relieved, except for the time the pessary is present in the vagina; but the moment it is removed, the stretch to which the coats of the vagina have been liable by its application, proves that the original cause of the disease is not in the least removed, but rather aggravated. It cannot be denied but that whilst the instrument is present (if large enongh) it serves to keep the uterus from falling downwards and outwards, but it does nothing towards removing the cause. All pessaries hitherto used have the same faults; and it appears strange that they should ever have been patronised, or even brought into use at all by medical mea, and only serves to prove, in mechanical skill, that the profession of medicine is at least far behind in the march of improvement.
What is the object proposed in relieving such cases as pessaries are applicable to, namely, where the laxity and debility of the parts are the cause of the uterus and its appendages falling down, so as even to protrude, and become a great source of annoyance? Why, simply to support the uterine mass in its natural position, by a means that will not add to the already too great dilatation of the vaginal canal, allowing the motions of the body to be executed without pain, and giving an opportunity? (whilst the means are employed) of allowing the debilitated and lax canal to regain its usual tone, strength, and dimensions. Such are the real objects in view; but $I$ would ask the reflecting person if such can be accomplished by the introduction of either ball or ring pessaries, of two or three times the dimensions of the canal in its natural state. I have seen them used of enormous size, more like foot-balls, or discs, than instruments designed for the vaginal canal. It is impossible, under such means, that permanent good can be effected. It would be useless for me to enter into the merits of the stem and pear-shaped pessaries, they are mere varieties of the ball and ring, which, without removing one of their evils, can only be recommended for the facility of their introduction and removal. If ou* olject was confined simply to support the uterus without any idea of removing the original cause, then some kind of pessary, such as hillierto known, would be sufficient, and then the question would arise which is the best in that view, I should prefer the inflated caoutchouc, as recommended by Mr. Goodman, of Manchester, or Dr. Haighton's sponge pessary. That the pessaries hitherto recommended may be useful to both practitioner and patient $I$ do not deny, but $I$ maintain that they are not based upon principles likely to effect permanent good.

To enter on the various mischiefs arising from wearing ball and ring pessaries, wouli extend this paper to a greater length than is intended; but how frequently do we meet with them in practice? Obstructions of the passages from the bladder and rectum, bruises, inflammatory action, ulceration, tumescence, pruritus, and a host of other inconveniences.

$I$ had a post-mortem examination some years ago of the body of an elderly female; the vagina presented the appearance of a stricture in the upper third: on examining closely, a large ring-pessary was found firmly impacted in the coats, and could only be extracted by cutting ont. An old neighbour-woman recollected her having one applicd twenty years before, but had heard nothing of it after, and supposed it had never been removed from its first application.

In proposing a new pessary, I am anxious it should be free from the evil tendencies 
common to those now in use; the only drawback attending it is the probability of its being more expensive, yet many will avail themselves of it, as it not only gives all the present relief afforded by the old plans, but it presents not the slightest hindrance to the parts regaining their healthy condition, natural dimensions, and greatly facilitates the application of local remedies to the seat of mischief. The instrument admits of easy explanation. It consists of a small shield of wood, ivory, \&c., of a peculiar shape, secured to the vaginal entrance by bandages attached to a belt applied around the body. To the inner surface of the shield is fitted a strong coil of steel wire, plated over with gold or silver, the dimensions of the coil being such, that when worn the vaginal canal will not be in the least extended, but with every facility assume its original dimensions. At the end of the coil is a caoutchouc ring, a little larger in dimensions than the coil on which the os uteri rests when applied. A profile view of the instrument would be as follows.

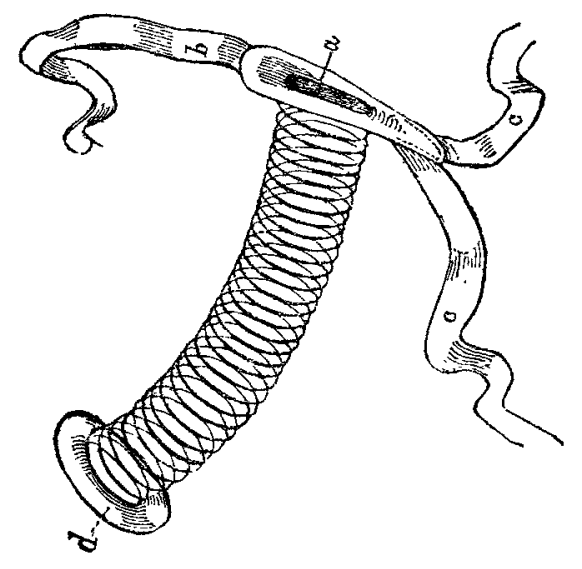

(a) The entrance of the vaginal canal in front of the shield.

(b) The anterior bandage, to fasten to the abdominal belt in front.

(c, c) Bandages to pass back between the thigh to the abdominal belt.

(d) The caoutchouc ring.

It must be evident, on reflection, that this plan possesses infinite advantages over the old pessaries, particularly in the following points of consideration:-First. The elasticity of the coil allows of the free motion of the body in every possible direction with perfect ease. Second. The vaginal canal not being obstructed, the catamenia can flow through the caoutchouc ring and along the coil withont any hindrance. Third. The dimensions of the coil and ring being so moderate, no undue pressure can prevent discharges either from the bladder or rectum. Fourth. The laxity of the vaginal canal may be removed, and its original dimensions restored (the measurements of the coil being not larger than the vaginal canal in a healthy condition). Fifth. Local applications for improving the tone of the parts are facilitated by the opening in front of the shield (marked $a$ ), through which injections can be thrown aud retained at pleasure, by introducing a small piece of sponge, or plug, in to the opening; and the same plan might be a protective to females in heated or crowded rooms, for sudden appearances of the catamenia.

It nust be borne in mind that the caoutchouc ring is some little larger than the coil, and the length of the coil must vary a little, according to circumstances: when it is weighted with the uterine mass, it should be about the length of the vaginal canal in a healthy state. I think a coil, varying from three and a half to four and a half inches will be found sufficient. To prevent any folds of the vaginal coats from getting entangled in the coil, a thin slip of caoutchouc is proposed to stretch along the under and outer surface of the coil.

Such is the instrument I wish to introduce. I have full confidence when manufactured by an able hand, that much good would result from its application. When the idea is made public, many hints perhaps may be given for its further improvement.

\section{DIAGNOSIS OF PREGNANCY WITH THREE CHILDREN.}

\section{To the Editor of THe LANCET.}

SIR :-Having noticed lately in Dr. West's translation of Dr. Naegele's useful little work, the very great rarity of an examination of a case of triplets by auscultators, I am induced to send for publication, if you think fit, the following case which came under my notice.

Mary Coleman, aged 30 , presented herself as a patient at the General Dispensary of this town on the 31st of July, 1840. Her tongue was foul, and bowels inactive; the abdomen was extremely large, and the thighs and legs very oedematous. She had supposed herself pregnant, but is now so large and her legs so much swelled that she thinks herself dropsical. Menstruation has ceased for some months.

On examination of the abdomen, the uterus was found extraordinarily enlarged. On applying the stethoscope the sound called "bruit placentum" was heard in the usual position, and the pulsations of three distinct foetal hearts in the following situations:Six inches to the right of the navel, and on a line drawn across the abdomen two inches below it, a foetal heart was heard beating distinctly; on the left side of the navel about six inches, and on the same transverse 